$\xi=-m$

\title{
Pattern of acute poisoning in teaching hospital, northwest Ethiopia
}

\author{
GetnetMequanintAdinew*, Assefa Belay Asrie \\ University of Gondar, College of Medicine and Health Science, School of Pharmacy, Department of Pharmacology, Gondar, Ethiopia \\ *Corresponding author E-mail:getnet.mequanint@yahoo.com
}

\begin{abstract}
Background: Acute poisoning is considered a major health problem worldwide and is a frequent cause of hospital admission. It is estimated that poisons are responsible for more than 1 million illnesses worldwide annually.

Objective: To evaluate retrospectively the pattern of acute poisoning in teaching hospital, northwest Ethiopia.

Materials and methods: This was an observational, retrospective study. The study population includes all patients who visiting Gondar teaching hospital emergency room who were diagnosed with acute poisoning from September 2010 to December 2014. All data were analyzed using SPSS 20.

Result: Acute poisoning cases constituted $0.67 \%$ of the 34320 admissions to the emergency department. Of these 233 patients, 148 $(63.5 \%)$ were female and $85(36.5 \%)$ were male.88.42\% were younger than 30 years of age and the frequency of acute poisoning declined with advanced age. Organophosphates were the most frequent cause of poisoning and accounted for 89 cases ( $38.2 \%)$. Intentional poisoning comprised $57.5 \% .83 .6 \%$ ( 195 cases) of the cases were ingested orally, the mean arrival time to the emergency unit after poisoning was 4.2 hours and the average duration of hospital stay was 11.26 hours. It was found that $60 \%$ of the cases were simply received supportive therapy. The most common factors contributing to intentional poisoning was quarreled with their family (54.2\%) followed by love affairs $(18.4 \%)$. The mortality rate was $0.43 \%$

Conclusions: The data observed in this hospital based shows acute poisoning remains a major public health problem with pesticide poisoning remaining the most common and therefore concerning poison.
\end{abstract}

Keywords: Antidote; Management; Organophosphate; Poisoning.

\section{Introduction}

Poison is any substance capable of producing damage or dysfunction in the body by itschemical activity. Advances in technology and social development have resulted in the widespread availability of most drugs and chemical substances in the community. These substances pose a significant threat due to their poisonous effects (Pokhrel2008). Poisoning due to accidental or deliberate ingestion, inhalation of medications and other chemicals is a common medical emergency. Unfortunately these communities the specific antidote may not always be available (Vivekanandan et al. 2012). Acute poisoning is considered a major worldwide health problem as well as a medico-social problem due to the number of hospital admissions (Lund et al.2012,Mahabalshetti et al.2013).

The global burden of poisoning is disproportionately borne by low and middle-income countries. this is caused by a combination of factors including greater exposure to hazardous products(PeirisJohn et al. 2013). It is estimated that some forms of poisons are directly or indirectly responsible for more than 1 million illnesses worldwide annually. The exact number is likely higher as most cases actually go unreported (Abd-Elhaleem et al.2014). This is because poisonings require rapid, early treatment and supportive care due to their severity, leaving little time for extensive investigations or diagnostics (Dines et al. 2007). Although recent data indicate that acute poisoning accounts for only $1 \%$ of emergency admissions , the medical costs of poisoning treatment can be substantial, exerting a considerable burden on the national health care service in developed and developing countries alike(Hanssens et al. 2001).

This study was undertaken to determine the pattern of acute poisoning in the Gondar, Ethiopia teaching hospital and to assess the risk factors that may influence the pattern. Relatively few studies have previously investigated this topic. Yet by understanding the general pattern of poisoning in a particular region may help to identify the risk factors leading to early diagnosis and management of such cases. In turn, this will lead to a reduction in morbidity and mortality rates. This study can be used to provide information about the agents most frequently involved in poisoning in this region as well as understanding ways to prevent future poisonings.

\section{Materials and methods}

This was an observational, retrospective study including all patients who visited the Gondar teaching hospital emergency room and were diagnosed with acute poisoning from September 2010 to December. The total study period was 51 months. All types of poisoning were included with a total sample of 233 poisoning cases. Gondar teaching hospital is a 300- bed referral hospital located in the Northern West part of Ethiopia. Data collection was performed using a pre- structured questionnaire. Data regarding age, sex, residence, types of poisoning, agents for poisoning, route of administration, seasonal variation, time elapsed, medical management receivedand final outcome was collected from the hospital records and documented in the pre- structured questionnaire. All cases were classified as either intentional or unintentional 
based on the information obtained from the document. Data collection was performed e by two clinical nurses trained on how to collect the data using the approved questionnaire. All data were entered and analyzed using Statistical Package for Social Sciences (SPSS 20). Continuous data was presented using mean with S.E.D. while categorical data was presented as frequency and percentage.

\section{Ethics statement}

Ethical approval for data collection was obtained from the ethics committees of the College of Medicine and Health Science (CMHS), University of Gondar (UoG). Permission to use medical records was confirmed by the hospital administrators. Confidentiality on the content of the medical records was maintained. The information was only utilized by the investigators for the research purpose.

\section{Results}

During the 51-month study period from 1 September 2010 to 30 December 2014, there were 34320 admissions to the emergency department. 233 of these patients were characterized as acute poisonings. This is an incidence rate $0.67 \%$ of 34320 . All types of poisoning exposures were observed throughout the various age categories. The ages of the patients ranged from 14 to 67 years. Of the 233 patients, $148(63.5 \%)$ were female and $85(36.5 \%)$ were male. In total, the female-to-male ratio was 1.74: 1 . It was found that 206 patients $(88.42 \%)$ were younger than 30 years of age and the frequency of poisoning as the age advanced. The mean with SEM age was $24.36+0.59$, in which the mean age of females were $23.58+0.77$ and males were $25.74+0.910$. The majority $(75.97 \%)$ of the poisoned patients resided in urban areas (Table 1). Organophosphates were the most frequent cause of poisoning and accounted for 89 cases $(38.2 \%)$. Sodium hypochlorite was the sec- ond most frequent cause of poisoning $(34.8 \%, 81$ cases), followed by drug $(6.9 \%, 16$ cases $)$ and $\mathrm{CO}(6.0 \%, 14$ cases $)$. In the remaining sixteen cases of poisoning $(6.9 \%)$, the substance involved was unidentified (Table 2). Intentional poisoning comprised $57.5 \%$ ( 134 cases) where as accidental poisoning comprised $23.2 \%$ (54 cases). It was clearly observed that female patients constituted the majority of suicidal poisoning $(41.63 \%, 97$ cases $)$. Moreover, a high percentage of suicidal patients $(88.42 \%, 206$ cases) were less than 30 years of age (Table 3). $44.2 \%$ of poisoning cases had to be admitted because of their seriousness. $39.5 \%$ of the poison cases were discharge from the emergency department after management and the remaining $16.3 \%$ were unknown and may have discharged by themselves (Table 4). 83.6\%( 195 cases) of the cases were ingested orally, followed by inhalational $(6.44 \%, 15$ cases) (Table 5 ). In the present study, $39.5 \%$ (92cases) of the cases presented to the emergency department within 2 hours of poisoning and the mean arrival time to the emergency unit after poisoning was $4.2 /$ hours. The average duration of hospital stay was 11.26hours (Fig. 1). It was noticed that $27 \%$ of the cases were simply received supportive therapy and, $24 \%$ were given atropine for the management of organophosphate poisoning cases. Among supportive therapy $17.6 \%$ (130 cases) underwent intestinal lavage, $6.4 \%$ received activated charcoal and 3\% (7 cases) received both gastric lavage and administration of charcoal for decontamination (Table 6). When observing the distribution of cases with respect to year, there was a dramatic increase from the year 2011 to 2014 (9 to $46.6 \%$ respectively) (Fig. 2). The distribution of poisoning according to month showed that the greatest numbers of patients were admitted in July (14.6\%). An apparent decrease in the number of patients was observed in March (2.6\%) (Fig. 3). The most commonly cited factor contributing to poisoning was quarreled with their family $(54.2 \%)$ followed by love affairs $(18.4 \%)$ (Table7). The mortality rate was $0.43 \%$

Table 1: Socio Demographic Characteristics

\begin{tabular}{|c|c|c|c|c|c|c|}
\hline Residence & Number & Frequency & & & & \\
\hline Urban & 177 & 75.97 & & & & \\
\hline \multirow[t]{2}{*}{ Rural } & 56 & 24.03 & & & & \\
\hline & Sex & & & & & \\
\hline \multirow[t]{2}{*}{ Age } & $\mathrm{F}$ & & M & & Total & \\
\hline & Number & Frequency & Number & Frequency & Number & Frequency \\
\hline$<10$ & 0 & 0 & 0 & 0 & 0 & 0 \\
\hline $11-20$ & 79 & 53.38 & 24 & 28.24 & 103 & 44.21 \\
\hline $21-30$ & 56 & 37.84 & 47 & 55.29 & 103 & 44.21 \\
\hline $41-50$ & 6 & 4.05 & 4 & 4.70 & 10 & 4.29 \\
\hline$>51$ & 2 & 1.35 & 3 & 3.53 & 5 & 2.14 \\
\hline Total & 148 & 100 & 85 & 100 & 233 & 100 \\
\hline
\end{tabular}

Table 2: Types of Poison

\begin{tabular}{lll}
\hline types & Number of cases & percentage \\
\hline OP & 89 & 38.2 \\
Bleaching agent & 81 & 34.8 \\
Organo chlorine & 5 & 2.1 \\
Benzene & 1 & 0.4 \\
Kerosen & 1 & 0.4 \\
$\mathrm{CO}$ & 14 & 6.0 \\
$\mathrm{H} 2 \mathrm{O} 2$ & 3 & 1.3 \\
Alcohol & 2 & 0.9 \\
herbal & 5 & 2.1 \\
Drug & 16 & 6.9 \\
Unknown chemicals & 16 & 6.9 \\
Total & 233 & 100 \\
\hline
\end{tabular}


Table 3: Reasons for Taking Poison with Respect to Age and Sex (N=233)

\begin{tabular}{|c|c|c|c|c|c|c|c|c|c|}
\hline Reason & Sex & $\begin{array}{l}\text { Age in year } \\
11-20\end{array}$ & $21-30$ & $31-40$ & $41-50$ & $>51$ & Total & percentage & \\
\hline \multirow{2}{*}{ Intentional } & $\mathrm{F}$ & 56 & 35 & 3 & 3 & & 97 & 41.63 & \multirow{2}{*}{$134(57.5 \%)$} \\
\hline & M & 15 & 18 & 3 & 1 & & 37 & 18.88 & \\
\hline \multirow{2}{*}{ Accidental } & $\mathrm{F}$ & 11 & 11 & 2 & 3 & 3 & 30 & 12.88 & \multirow{2}{*}{$54(23.2 \%)$} \\
\hline & M & 8 & 13 & 1 & 2 & & 24 & 10.30 & \\
\hline \multirow{2}{*}{ Unknown } & $\mathrm{F}$ & 4 & 14 & & 1 & & 19 & 8.15 & \multirow{3}{*}{$45(19.3 \%)$} \\
\hline & M & 9 & 12 & 3 & & 2 & 26 & 11.16 & \\
\hline Total & & 103 & 103 & 12 & 10 & 5 & 233 & 100 & \\
\hline
\end{tabular}

Table 4: Types of Disposal of Patients

\begin{tabular}{lll}
\hline disposal & Number of cases & percentage \\
\hline Discharged from ER & 112 & 48.07 \\
Admitted & 81 & 34.76 \\
Unknown/disappear & 39 & 16.74 \\
Died & 1 & 0.43 \\
Total & 233 & 100 \\
\hline
\end{tabular}

Table 5: Rout of Administration

\begin{tabular}{lll}
\hline route & Number of cases & percentage \\
\hline Oral & 195 & 83.69 \\
Inhalational & 15 & 6.44 \\
Contact & 3 & 1.29 \\
Unknown & 20 & 8.58 \\
total & 233 & 100 \\
\hline
\end{tabular}



Fig. 1:Arrival Time to the Emergency Unit after Poisoning. The Blue Color Indicates the Number of Cases and the Red Color Indicates the Percentage of Cases.

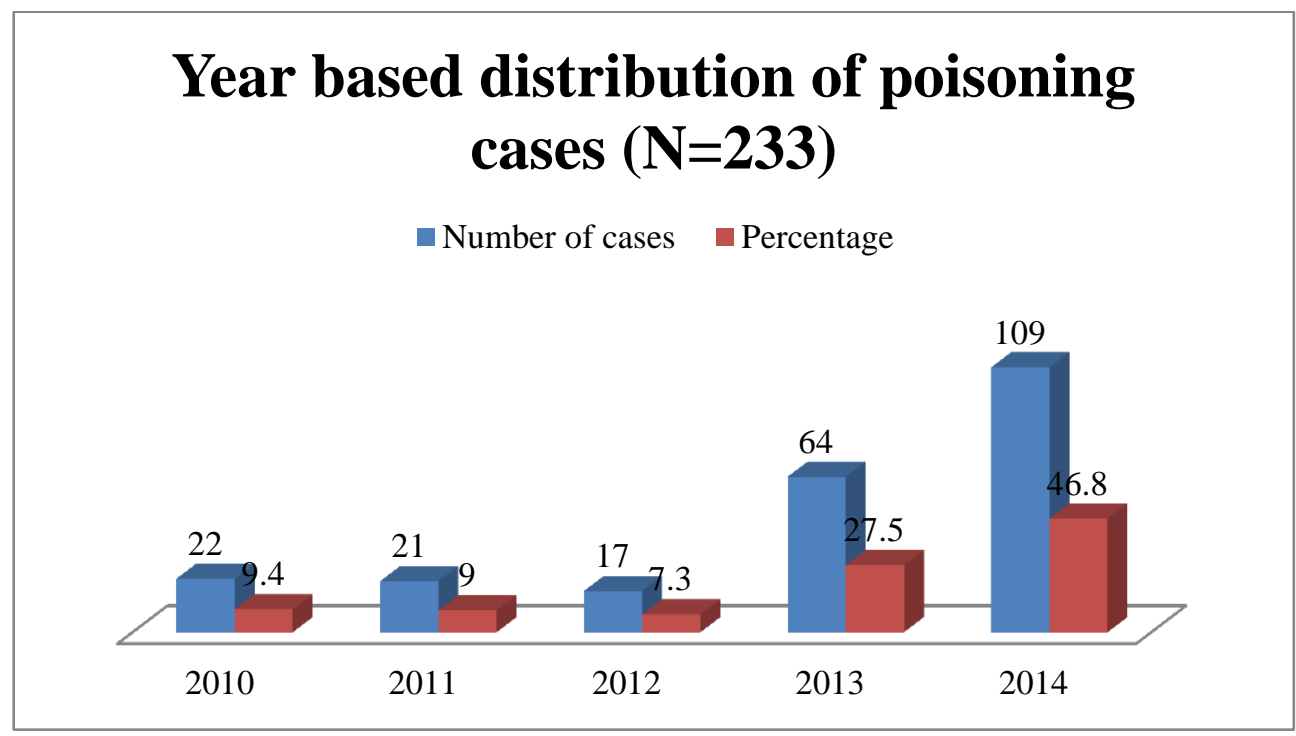

Fig. 2: Yearly Distribution of Poisoning Cases. TheBlue Color Indicates the Number of Cases and the Red Color Indicates the Percentage of Cases. 


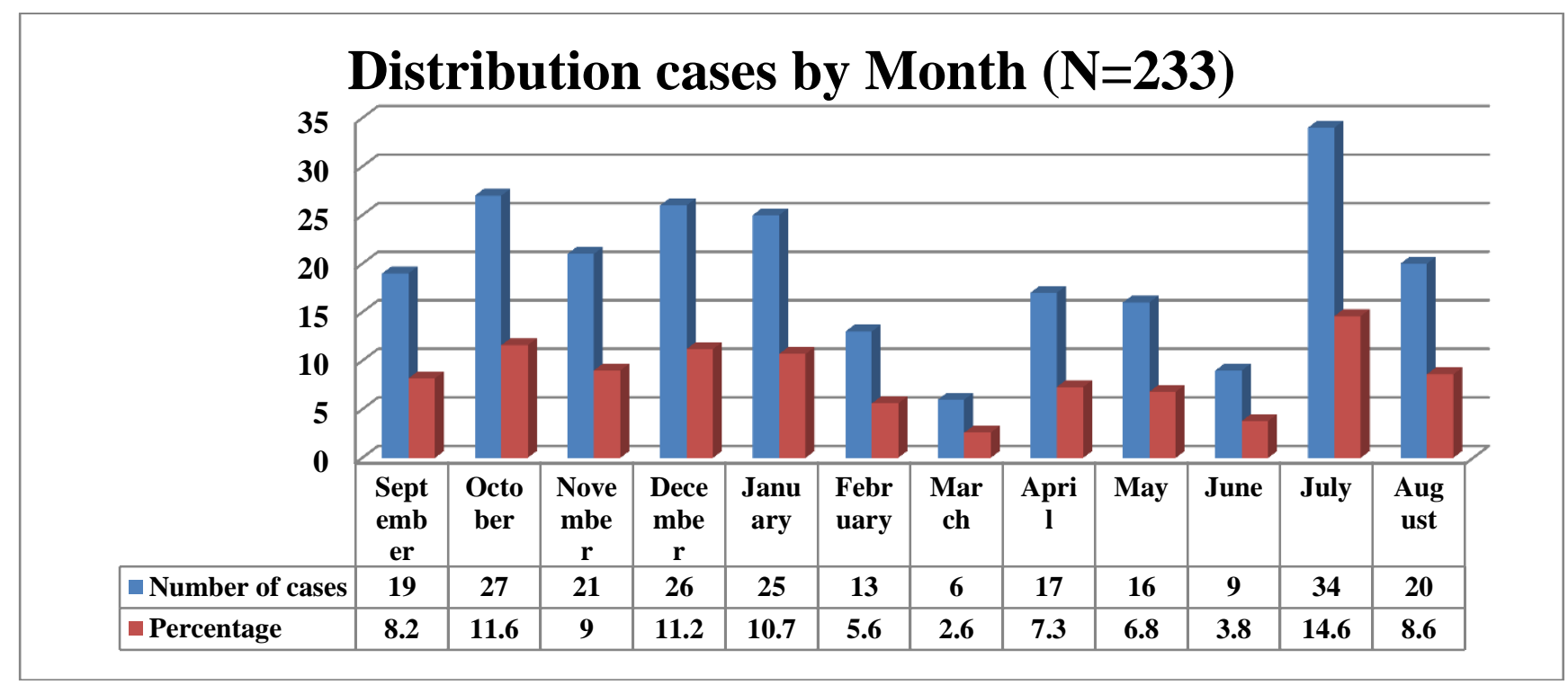

Fig. 3: Monthly Distribution of Poisoning Cases. The Blue Color Indicates the Number of Cases and the Red Color Indicates the Percentage of Cases.

\section{Discussion}

Two hundred thirty three patients presented to the emergency department during the study period due to acute poisoning. This accounted for $0.67 \%$ of the total emergency room admissions. This percentage is increased when compared to the previous study performedin Ethiopia (0.45\%) (Tefera et al. 2006) and similar with other findings worldwide (Güloğlu et al.2004).Of the 233 patients observed, a large majority $(88.42 \%)$ were younger than 30 years of old, while the population greater than 50 years old presented the smallest percent $(2.14 \%)$ and were mostly unintentional poisonings. This represents a smaller percentage than seen in prior documentation (Hegazy et al.2012). Other studies reportedrates of mostly accidental poisonings of $2.3 \%$ to $5.3 \%$ in patients over 60 years old ( $\mathrm{Hu}$ et al. 2010). This study reveals that the pattern of acute self poisoning in female patients was $63.5 \%$ where as male patients were $36.5 \%$. The female to male ratio was $1.74: 1$. Similar results were found in other studies (SB et al. 2005). However, a male preponderance was reported elsewhere (Vivekanandan et al. 2012). It is hypothesized that the reason females attempt suicide at a higher rate than males in Ethiopia may be due cultural practices towards them; most young females are more critically followed and closely controlled by their family when we compare with males. Therefore, females are more likely to hide certain behaviors, such as intimate relationships with the opposite sex to avoid conflict or disapproval. However, when these behaviors are found out, it may cause more family and personal conflict leading to a suicide attempt with different poisons or drugs. This may also explain this study's finding that the most common reason $(57.5 \%)$ given for intentional poisoning was family conflict. this finding was reflected in other studies(Vivekanandan et al. 2012). The higher rate of intentional poisoning deemed, within women aged 10-30 years, is a pattern observed in many low and middleincome countries including New Zealand and other countries (Peiris-John et al. 2013). Studies from both developed and developing countries demonstrate that young people, particularly women, below 30 years are over represented in self harm admission (Cheung et al. 2005). Overall these groups are emotionally labile and they are not mature enough to tolerate extreme mental or physical pressure (Sharma et al.2010).

The results of the present study indicated that the majority of adults (about $75.97 \%$ ) live in urban areas. This is in accordance with other studies. This pattern can be explained by the presence of chemicals and other toxic materials in urban communities as well as access to the Gondar Hospital for treatment which draws from a more urban population. Rural populations are more likely to be treated in rural dispensaries or district hospitals (Hegazy et al. 2012).

It was noticed that intentional poisonings (134 cases, $57.5 \%$ ) occurred most frequently in the adult group, Similar findings were also reported by other studies (Singh et al. 2014), with rates exceeding 90\% (Mahabalshetti et al.2013). The increase in number of self poisonings may be due to many factors such as increases in unemployment, urbanization, reductionin family support system, relationship failure, economic instability,an individual's frustrations, lack of coping skills in social or behaviors, impulsive behaviors, stress due to job and family etc(Mahabalshetti et al.2013). Contrary to this study, accidental poisoning was the most common manner for poisoning representing $64.6 \%$ in King Khaled Hospital in Al Majmaah, Saudi Arabia (Abd-Elhaleem et al.2014).

Poisoning cases are increasing day by day due to changes in the lifestyle and social behavior in northern Ethiopia (UB et al.2015). In this study, the number of poisoning cases increased from year to year, which might be due to increased access to chemicals when compared to previous years. It also may be due the economic growth of the country and the associated increased availability of different agrochemicals in the country. This study showed an increase in cases from9 to $46.6 \%$ between the years 2011 to 2014 an observation that is in agreement with other studies (Moazzam et al 2009). When the data was analyzed by month, July was found to have the greatest number of admitted patients $(14.6 \%)$.This is likely because it is the month when the most chemicals are used by farmers to increase their crop yield.An apparent decrease in the number of the patients was observed in March (2.6\%), which is likely due to seasonal variation. In general more cases were reported during spring $(28.8 \%)$ followed by the rainy and winter season $(27.5 \%$ and $27 \%$ respectively), which was similar with other findings (Jalali et al. 2012). However, other studies found the incidence during summer to be higher (Maharani et al.2013). Poisonous agents show geographical variations depending on economic status. In developed countries, poisonings aremostly due to drugs, cosmetics and beauty products, household cleansing products and alcohol, while in developing countries, where the economy is basedon agriculture, common causes of poisoning are hydrocarbons, pesticides, traditional medicines and mushrooms (Abd-Elhaleem et al.2014). This is consistent with the present study where organophosphate poisonings were predominant. The easy availability of these agrochemicals in the region and at home might also contribute to the high level of consumption (Mar et al. 2008). According to a community study, the high number of pesticide self-poisonings was explained as an impulsive response to economically or psychosocially stressful events facilitated by easy access to pesticides (F et al. 2006). The high number of organo- 
phosphate poisoning in this study may relate to the agricultural practices of the population which includes wide use of pesticides. The most commonly recorded route was ingestion $(83.6 \%)$, which is similar with other findings (SB et al. 2005, Sharma et al .2010).Liquid and solid forms were the most common forms reported: $136(58.4 \%)$ and 58 cases (24.9\%) respectively, which was consistent with previous studies (Moazzam et al. 2009).

Most of the casespresentedto the emergency room within 2 hours of poison ingestion $(39.5 \%)$, this is consistent with other findings $(23,24)$. The mean delay between consumption of poison and presentation to the hospital was $4.2 \mathrm{hrs}$, which was also similar with other findings (Ahuja et al. 2015). Time to presentation at a health care facility is critical and correlates with overall prognosis and rate of mortality. Early presentation facilitates immediate and effective treatment. Time from the ingestion of poison to the time of presentation at the hospital was significantly less among survivors than that among expired ones (s et al. 2009). A short length of stay in the hospital (in this study an average of 11.26hours) is one of the merit of managing intoxicated patients versus other investigations that reported a longer in-hospital length of stay(62.4hrs) (Peiris-John et al. 2013).

Management of these critically ill patients will greatly improve if the common causes of poisoning are properly defined (Mahabalshetti et al.2013). Currently treatment predominantly comprises of supportive and symptomatic therapy (66\%) which indicates lack of clear-diagnosis and treatment guidelines for the majority of the cases. The challenge for the attending clinician is in early identification of patients at risk of developing serious clinical toxicity, and who may benefit from decontamination or a specific intervention. Most patients were treated with supportive measures, and about $27 \%$ and $24 \%$ of the patients were given gastrointestinal decontamination and specific antidotes respectively. For lavage therapy, activated charcoal and Atropine were the most common.Clinicians use Atropine for the treatment of organophosphate poisoning cases, which acts as a competitive antagonist at both the central and peripheral muscarinic receptors. It is an effective in the treatment of exposures to muscarinic agonists and acetylcholinesterase inhibitors (Pillay et al. 2008). In this study $23.18 \%$ (54cases) of the organophosphate poisoning cases did not receive an antidote even if they arrived within $2 \mathrm{hrs}$ to the emergency department.All carbon monoxide poisoning cases were administered oxygen which is the agreed safe and effective treatment. Some of the other treatment that were observed during this study were found to be contraindicated when compared to accepted standards. For examples charcoal, lavage is not recommended for comatose patients however, it was reportedly administered irrespective of the time of ingestion of the poison (>than 24 hours) or the patient's condition. Most scholars agree that gastric lavage is not recommended if it has been more than 2hours since ingestion. In practice this suggestion is not always followed. Another example is the use of activated charcoal which appears to be mostefficacious when given within an hour of ingestion (28), and other studies reported gastric lavageis usually not helpful beyond 4 hours of ingestion(29) but both of them were not followed in the present study. Irrespective of the time, gastric lavage is performed in this hospital, as the initial part of treatment.

Overall in-hospital mortality rates are less than $0.5 \%$ which is similar with the present study (the mortality rate $0.43 \%$ ) (Greene et al. 2005), however the medical costs of poisoning treatment can be substantial, exerting a considerable burden on the national health care service in developed and developing countries (Hanssens et al. 2001).

\section{Limitations of the study}

Our study has some limitations, the most important of which is selection bias. Only poisoning cases treated in the university hospital emergency department were included in the study, therefore the results likely reflect more severe poisonings than occur in a general population. The poisoning cases admitted to other wards were not included and poisoning cases that were admitted to private clinics or treated at home were also not included in this analysis. Therefore, the frequency of poisoning presented in this study likely under-estimate the frequency of poisonings. Finally, this study is retrospective hence results may vary with present trends.

\section{Conclusions}

Even though it is a hospital based study, the result suggest that acute poisoning remains a major public health problem in this teaching hospital, with pesticide poisoning remaining the most important. However, cases of sodium hypochlorite poisoning have recently increased. Youth in the communities remain very vulnerable population; the cumulative incidence of poisoning for young females was high.This represents a very high risk group who should be targeted in primary prevention programs. Additionally strict regulations regarding the storage and sale of pesticides and chemicals should be implemented. Patients with suicidal poisoning should undergo psychiatric consultation to reduce the risk of future attempts. For this hospital, it is recommended that they have toxicology screening tests on hand for proper identification of the type of poison which can hasten the proper management of these cases. Also improving medical record-keeping is also suggested for a better information access to understand patterns. And finally, a poison control center should be established in this hospital to ensure good record keeping, resources and easy availability of antidotes.

\section{Acknowledgment}

Sincere gratitude is expressed to University of Gondar for their financial backing, cooperation and continuous support throughout this work and Anna Bazinet for language editing.

\section{Conflict of interest}

Adinew GM and Assefa BA declare that they have no conflict of interest.

\section{References}

[1] Pokhrel D, Pant S, Pradhan A, Mansoor S (2008) a comparative retrospective study of poisoning cases in central, zonal and district hospitals. Kathmandu university journal of science, engineering and technology I (V):40-8.

[2] Vivekanandan.K, Bhavya.E, K.Punitha, Anand V (2012) A study on poison cases and their management along with poison awareness educational strategies. Asian Journal of Pharmaceutical and Clinical Research 5(2).

[3] Lund C, Vallersnes OM, Jacobsen D, Ekeberg O, Hovda KE (2012) Outpatient treatment of acute poisonings in Oslo: poisoning pattern, factors associated with hospitalization, and mortality. Scandinavian Journal of Trauma, Resuscitation and Emergency Medicine 20(1).http://dx.doi.org/10.1186/1757-7241-20-1.

[4] Mahabalshetti AD, Aithal KR, Patil BS, Kudari SS, Dhananjaya M (2013) Profile of acute poisoning cases at a tertiary care hospital. MedicaInnovatica 2(1).

[5] Peiris-John R, Kafoa B, Wainiqolo I, Reddy RK, McCaig E, Ameratunga SN (2013) Population-based characteristics of fatal and hospital admissions for poisoning in Fiji: TRIP Project-11. InjPrev 19:355-7.http://dx.doi.org/10.1136/injuryprev-2012-040651.

[6] Abd-Elhaleem ZAE, Muqhem BAA (2014) Pattern of acute poisoning in Al Majmaah region, Saudi Arabia. American Journal of Clinical and Experimental Medicine 2(4):79-85.

[7] Dines A, Archer J, Dargan P, Collignon U, Nash S (2007) Poisoning an overview of treatment. Hospital Pharmacist 14.

[8] Hanssens Y, Deleu D, Taqi A (2001) Etiologic and Demographic Characteristics of Poisoning: A Prospective Hospital-Based Study in Oman. Clinical Toxicology 39(4):37180.http://dx.doi.org/10.1081/CLT-100105158.

[9] Tefera A, Y W (2006) the pattern of acute poisoning in a teaching hospital, north-west Ethiopia. Ethiop Med J 44(2):183-9. 
[10] Güloğlu C, Kara IH (2004) Cases of Acute Poisoning in Southeast Anatolia of Turkey. Dicle Tip Dergisi 31(2):37-45.

[11] Hegazy R, Almalki WH, Afify RHM (2012) Pattern of Acute Poisoning in Makkah Region Saudi Arabia. The Egyptian Journal of Community Medicine 30(1).

[12] Hu Y-H, Chou H-L, Lu W-H, Huang H-H, Yang C-C, Yen DHT, et al (2010) Features and Prognostic Factors for Elderly With Acute Poisoning in the Emergency Department. J Chin Med Assoc73 (2):78-87.http://dx.doi.org/10.1016/S1726-4901(10)70006-X.

[13] SB K, SB A (2005) A study of poisoning cases in emergency Kathmandu Medical College Teaching Hospital. Kathmandu University Medical Journal 3(12):388-91.

[14] Cheung CY, Tat FH, Keung LC, Hon TS, Kwok NH, Yee SM, et al (2005) A prospective epidemiological study of acute poisoning in Hong Kong. Hong Kong jemergmed 12:156-61.

[15] B.R.Sharma, D.Harish, A.K.Sharma, Bangar S, Gupta M, Gupta N, et al (2010) Toxicological emergencies and thier management at different health care levels in Northern India-An overview. Journal of pharmacology and Toxicology 5(7):418-30.

[16] Singh OG, Singh AM (2014) Trends of poisoning cases in Melmaruvathur region of Tamil Nadu: A retrospective study of 3 years. IAIM 1(4):27-31.

[17] UB G, Tadvi NA, Hussain S (2015) A comparative overview of poisoning in multidimentional perspective. Int $\mathrm{J}$ Med Res Health Sci 4(1):203-7.http://dx.doi.org/10.5958/2319-5886.2015.00033.8

[18] Moazzam M, Al-Saigul AM, Naguib M, Alfi MAA (2009) Pattern of acute poisoning in AlQassim region: a surveillance report from Saudi Arabia, 1999-2003. Eastern Mediterranean Health Journal 15(4).

[19] Jalali A, Savari M, Dehdardargahi S, Azarpanah A (2012) The Pattern of Poisoning in Southwestern Region of Iran: Envenoming as the Major Cause. Jundishapur J Nat Pharm Prod 7(3):100 5.http://dx.doi.org/10.17795/jinpp-3504.

[20] Maharani B, Vijayakumari N (2013) Profile of poisoning cases in a Tertiary care Hospital, Tamil Nadu,India. Journal of Applied Pharmaceutical Science3 (01):0914.http://dx.doi.org/10.7324/japs.2013.30117.

[21] Mar H, Mhi S, Mr a, Mg M, Ms I, Mz U, et al (2008) Clinicoepidemiological pattern of poisoning in a tertiary level hospital. J Dhaka Med Col17 (2):111-5.

[22] F K, Wv H, P P (2006) Reaching for the bottle of pesticide--a cry for help. Self-inflicted poisonings in Sri Lanka. SocSci Med 62(7):1710-9.http://dx.doi.org/10.1016/j.socscimed.2005.08.020.

[23] Singh DP, Aacharya RP (2006) Pattern of poisoning cases in Bir Hospital. Journal of Institute of Medicine 28(1):3-6.

[24] Kishore PV, Palaian S, Paudel R, Mishra D, Ojha P, Alam K, et al (2008) Pattern of poisoning cases in a teaching hospital in Western Nepal. Journal of Institute of Medicine30 (1):26-34

[25] AHujA H, mAtHAi AS, PAnnu A, ArorA r (2015) Acute Poisonings Admitted to a Tertiary Level Intensive Care Unit in Northern India: Patient Profile and Outcomes. Journal of Clinical and Diagnostic Research9 (10).

[26] S B, P P, D S, NK B, AK D, GS S, et al (2009) Clinical profile and outcome of children presenting with poisoning or intoxication: a hospital based study. Nepal Med Coll J11 (3):170-5.

[27] Pillay V (2008) Current Views on Antidotal Therapy in Managing Cases of Poisoning and Overdose. JAPI 56.

[28] Albertson TE, Owen KP, Sutter ME, Chan AL (2011) Gastrointestinal decontamination in the acutely poisoned patient. International Journal of Emergency Medicine4 (65).http://dx.doi.org/10.1186/1865-1380-4-65.

[29] Harish D, Chavali KH, Singh A, Kumar A (2011) Recent Advances in the Management of Poisoning Cases. J Indian Acad Forensic Med33 (1).

[30] Greene SL, Dargan PI, Jones AL (2005) Acute poisoning: understanding $90 \%$ of cases in a nutshell. Postgrad Med J 81:204 16.http://dx.doi.org/10.1136/pgmj.2004.024794.

[31] Hanssens o, Deleu D, Y AT (2001) Etiologic and Demographic Characteristics of Poisoning: A Prospective Hospital-Based Study in Oman Clinical Toxicology39 (4):371-80 